\title{
New Perspectives for Anatomical and Molecular Studies of Kisspeptin Neurons in the Aging Human Brain
}

\author{
Erik Hrabovszky Szabolcs Takács Balázs Göcz Katalin Skrapits \\ Laboratory of Reproductive Neurobiology, Institute of Experimental Medicine, Hungarian Academy of Sciences, \\ Budapest, Hungary
}

\section{Keywords}

Gonadotropin-releasing hormone $\cdot$ Hypothalamus . Immunohistochemistry · Kisspeptin · LHRH · Neurokinin B · Reproduction

\begin{abstract}
The human infundibular nucleus (corresponding to the rodent arcuate nucleus) serves as an important integration center for neuronal signals and hormones released by peripheral endocrine organs. Kisspeptin (KP)-producing neurons of this anatomical site, many of which also synthesize neurokinin $B(N K B)$, are critically involved in sex hormone signaling to gonadotropin-releasing hormone $(\mathrm{GnRH})$ neurons. In recent years, the basic topography, morphology, neuropeptide content, and connectivity of human KP neurons have been investigated with in situ hybridization and immunohistochemistry on postmortem tissues. These studies revealed that human KP neurons differ neurochemically from their rodent counterparts and show robust aging-related plasticity. Earlier immunohistochemical experiments also provided evidence for temporal changes in the hypothalamus of aging men whose NKB and KP neurons undergo hy-
\end{abstract}

(92019 S. Karger AG, Basel

E-Mail karger@karger.com www.karger.com/nen pertrophy, increase in number, exhibit increased neuropeptide mRNA expression and immunoreactivity and give rise to higher numbers of immunoreactive fibers and afferent contacts onto $\mathrm{GnRH}$ neurons. Increasing percentages of KP-expressing NKB perikarya, NKB axons, and NKB inputs to GnRH neurons raise the intriguing possibility that a significant subset of NKB neurons begins to cosynthesize KP as aging advances. Although use of postmortem tissues is technically challenging, recently available single-cell anatomical and molecular approaches discussed in this review provide promising new tools to investigate the aging-related anatomical and functional plasticity of the human KP neuronal system.

(2019 S. Karger AG, Basel

\section{Introduction}

Hypothalamic kisspeptin (KP)/KP receptor signaling is critical for mammalian puberty and fertility $[1,2]$. The topography, morphology, connectivity, and plasticity of human KP neurons was reviewed in this Journal 5 years ago [3]. In the present minireview, we briefly summarize 
the current state-of-the-art, recent developments and future perspectives of single-cell anatomical and molecular research on postmortem human hypothalamic tissues, with a focus on plastic changes of the KP system during reproductive aging.

\section{Topography and Structure of Human KP Neurons}

The regional distribution of KP neurons in the human hypothalamus has been studied and clarified with in situ hybridization [4] and immunohistochemistry $[3,5]$. The results of these anatomical studies agreed that the bulk of $\mathrm{KP}$ cells is located in the caudal infundibular nucleus (INF). In addition, immunohistochemical mapping experiments revealed a relatively lightly labeled second neuronal population in the rostral periventricular area of the third ventricle in female subjects [3]. Given that positive estrogen feedback might be regulated by a similarly located sexually dimorphic (more abundant in females) preoptic cell group in laboratory rodents [6], the observation of this second KP cell population in humans is conceptually interesting. Currently, positive estrogen feedback in primates is thought to take place primarily in the mediobasal hypothalamus $[7,8]$. In humans, the pituitary also seems to play a considerable role in the preovulatory LH surge $[9,10]$, whereas no solid evidence exists to support the reproductive significance of the preoptic area. The human hypothalamus also contains a third KP-immunoreactive (IR) cell population which consists of scattered periventricular neurons that can be immunostained relatively heavily $[3,5]$.

It is interesting to note that the rodent brain contains extrahypothalamic KP neurons as well within the medial amygdala, the bed nucleus of the stria terminalis, and the lateral septum [11]. The issue of whether or not equivalent cell groups exist in the human brain will require clarification. Earlier we observed a dense KP-IR axon plexus in the human bed nucleus of the stria terminalis. The absence of neurokinin $B(\mathrm{NKB})$ in these fibers [5] raises the possibility of their local origin.

The basic shape of individual KP-IR neurons has been established in our laboratory using $100-\mu \mathrm{m}$-thick sections [12]. The majority of human KP neurons (79.3\%) are bipolar, with two primary dendrites, as also reported in mice [13]. In addition, we have observed tripolar (three primary dendrites; 14.1\%) and unipolar (a single emerging dendrite; 6.6\%) neuronal phenotypes which have not been reported in earlier studies of rodents [13] (Fig. 1).

\section{Species-Specific Neurochemistry of the Human KP Cell}

Important species differences exist between the neurochemistry of KP neurons in humans versus rodents, as reviewed recently [14]. Accordingly, the colocalization between KP and NKB is only partial in humans. While independently of sex and age, the majority of human KP neurons express NKB, the colocalization in the opposite direction is more limited and depends significantly on the age and the sex of the subjects $[15,16]$; the highest percentage of KP-expressing NKB neurons (84\%) has been detected in postmenopausal women and the lowest (36\%) in young men (Fig. 2a) [14, 17]. Dynorphin, which is detectable in the majority of KP cells in the sheep [18] and in rodents [19], can be visualized very rarely with immunohistochemistry in human KP cells $[14,17]$. It is worth to note that tissue samples from premenopausal women having higher prodynorphin-expressing cell numbers in the INF than postmenopausal women [20] have not been tested yet in this context. Another technical consideration is that alternative splicing [21] and/processing of prodynorphin by human KP cells may result in protein fragments unrecognized by the dynorphin $\mathrm{A}$ and dynorphin $B$ antibodies used in previous colocalization experiments [17].

Similarly to dynorphin, galanin is also present in murine [22, 23], but not in human, KP neurons. Conversely, neuropeptides showing species-specific colocalization with KP in humans, but not in laboratory rodents, include substance P [24] and cocaine- and amphetamineregulated transcript [25] (Fig. 2b), as we reviewed recently [14].

Fig. 1. Distribution and morphology of kisspeptin (KP)-immunoreactive neurons in the caudal infundibular nucleus (INF) of postmenopausal women. a The majority of labeled neurons are present in the caudal INF and the infundibular stalk (InfS), as shown in a representative $30-\mu \mathrm{m}$-thick section of a 57 -year-old woman. b-f The analysis of non-truncated neurons in $100-\mu \mathrm{m}$-thick sections of a 72-year-old female reveals that KP neurons have two ( $\mathrm{B}=\mathrm{bi}$ polar neuron; $79.3 \%)$, three $(\mathrm{T}=$ tripolar neuron; $14.1 \%)$, and occasionally only one ( $\mathrm{U}=$ unipolar neuron; $6.6 \%)$ primary dendrite. $\mathrm{DMH}$, dorsomedial nucleus of the hypothalamus; fx, fornix; opt, optic tract; $\mathrm{VMH}$, ventromedial nucleus of the hypothalamus; $3 \mathrm{~V}$, third ventricle. Scale bar shown in $\mathbf{f}=100 \mu \mathrm{m}$ in $\mathbf{a}$ and $25 \mu \mathrm{m}$ in b-f. The image has been reproduced with permission from Takács et al. [12].

(For figure see next page.)

Neuroendocrinology 2019;109:230-241

231 


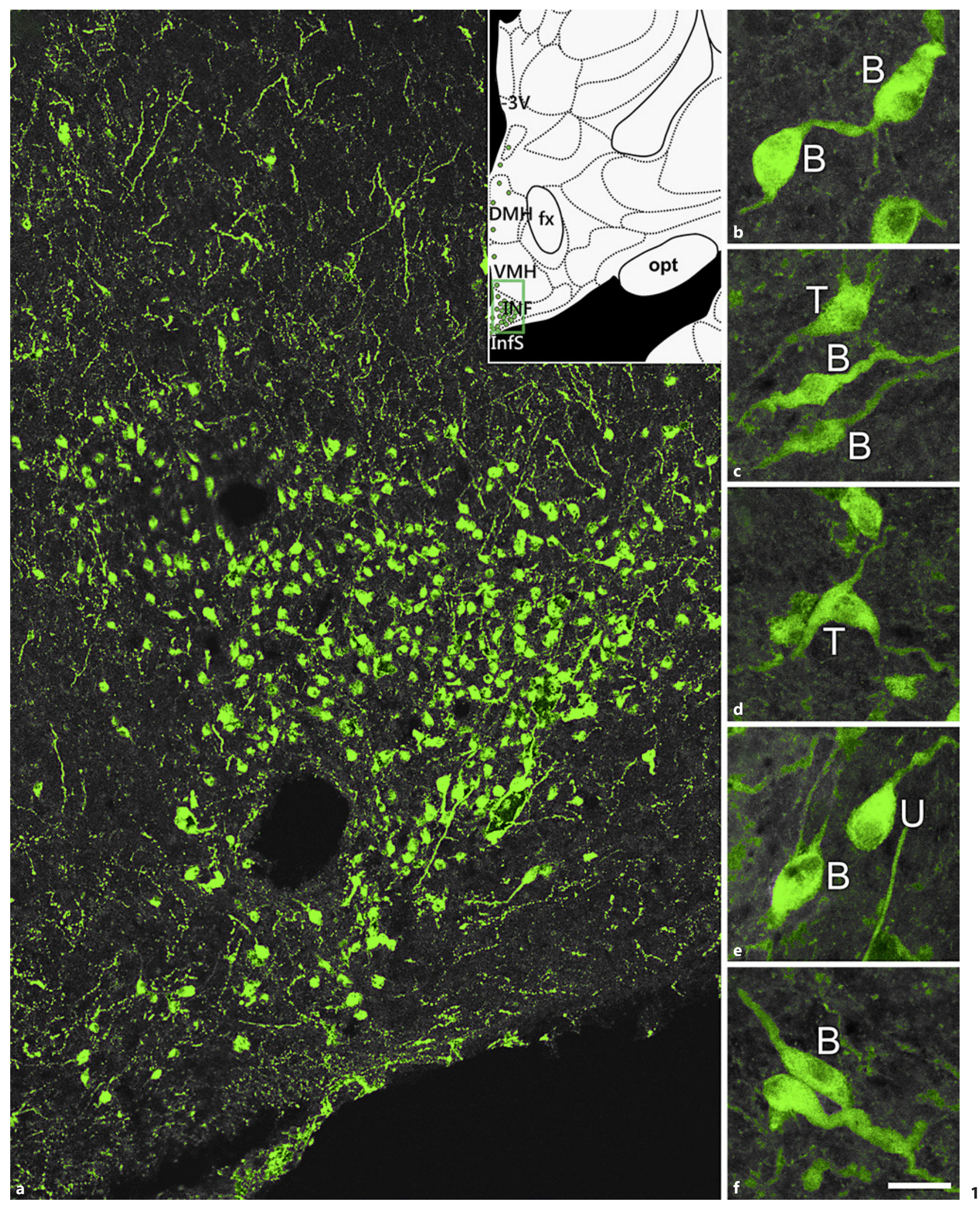




\section{Menopausal Alterations}

In 1966, Sheehan and Kovács reported hypertrophied neurons with enlarged nuclei and nucleoli and a prominent Nissl substance in the INF of postmenopausal women and of women with postpartum hypopituitarism. They attributed these anatomical changes to ovarian failure [26]. Later, in situ hybridization studies from Rance and coworkers demonstrated the expression of the mRNAs encoding estrogen receptor- $\alpha$ [27], substance P [28], NKB [28], KP [4], and prodynorphin [20] in these hyper- trophied cells. Subsequent studies from our laboratory used quantitative immunohistochemical analyses to compare sex differences between KP and NKB neurons in postmenopausal women ( $>55$ years) and middle-aged/ aged ( $\geq 50$ years) men [15]. These studies confirmed the postmenopausal neuronal hypertrophy and showed twice as large profile areas for KP neurons in females than in age-matched males. NKB labeling was generally more abundant than KP labeling in both sexes, whereas quantifiable parameters of KP immunoreactivity differed more robustly between the two groups. The number of KP cell
Fig. 2. Age- and sex effects on the cosynthesis of kisspeptin (KP) in neurokinin $B$ $(\mathrm{NKB})$ neurons and on the incidences of $\mathrm{KP}$ and NKB afferents to gonadotropin-releasing hormone neurons. a KP and NKB signals and the extent of their colocalization show robust sex and age dependence in the human. Independently of the sex and age of the subject, most KP neurons express $\mathrm{NKB}$, whereas colocalization in the opposite direction is limited and highly sex and age dependent. Accordingly, the percentage of NKB neurons that also contain KP increases from $36 \%$ in young ( $<50$ years) to $69 \%$ in middle-aged/aged ( $\geq 50$ years) adult male individuals. An even higher percentage $(84 \%)$ can be found in samples from postmenopausal women. $\mathbf{b}$ The neuropeptide complement of human KP neurons differs considerably from that of laboratory rodents and the sheep. Unlike rodent KP neurons, human KP cells do not contain galanin and rarely seem to contain dynorphin, whereas they express substance $\mathrm{P}$ (SP) and cocaine- and amphetamine-regulated transcript (CART) peptide immunoreactivities. Arrowheads in immunofluorescent insets point to quadruple-IR axon varicosities coexpressing the $\mathrm{KP}, \mathrm{NKB}, \mathrm{SP}$, and CART immunofluorescent signals. c The incidences of KP-IR and NKB-IR afferent contacts onto the cell bodies and dendrites of $\mathrm{GnRH}$ neurons also vary with age and sex. Both axosomatic and axodendritic inputs increase with age in males, and the highest numbers can be observed in postmenopausal women. Note that similar quantitative immunohistochemical data from premenopausal women are currently unavailable. For more thorough description of the above data, see original reports [14-17, 24, 25].

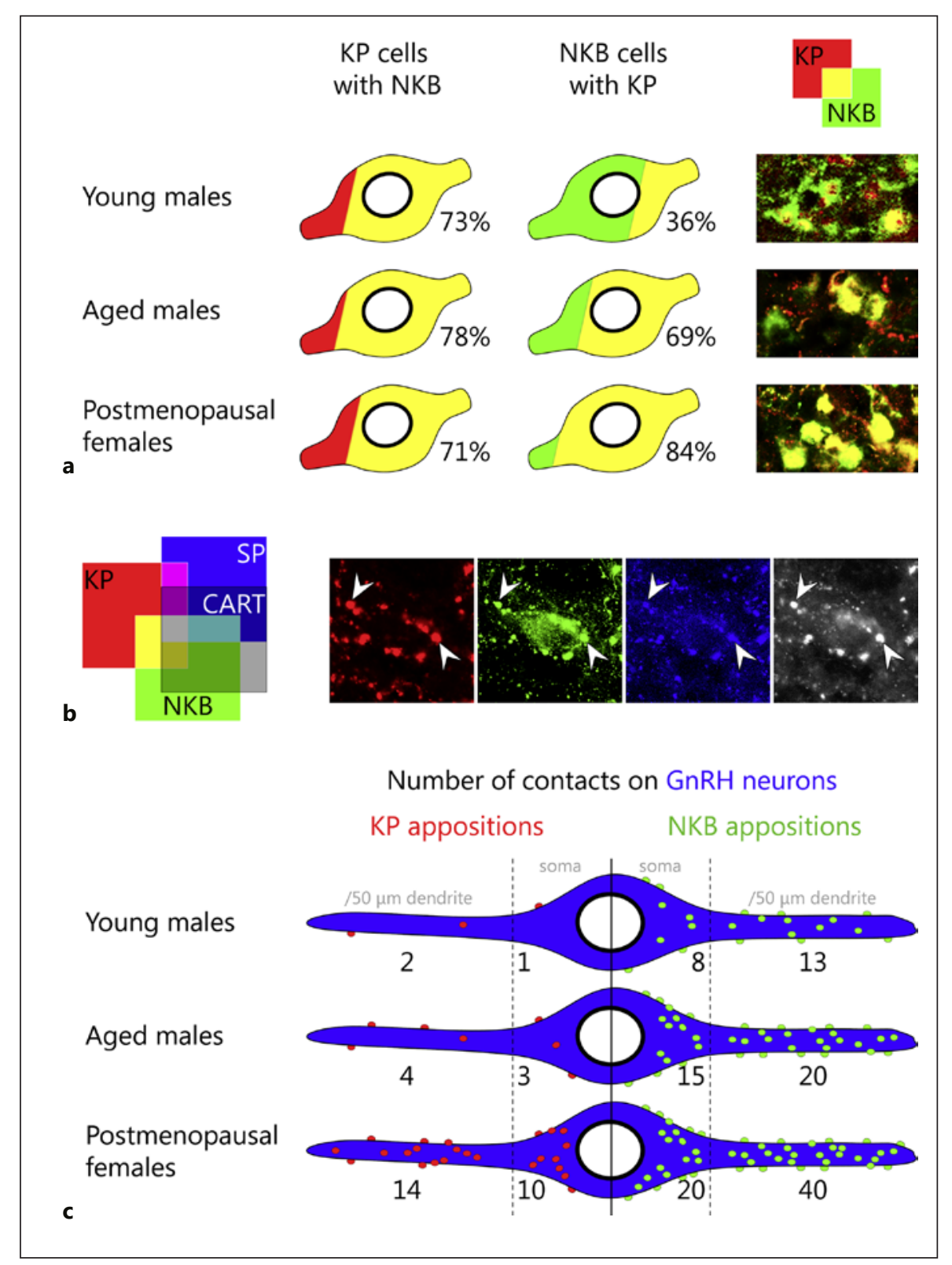

Neuroendocrinology 2019;109:230-241 
bodies, the density of KP fibers, and the incidence of their contacts on gonadotropin-releasing hormone $(\mathrm{GnRH})$ neurons (Fig. 2c) were much higher in middle aged/aged women compared with men [15]. The immunohistochemical signal for NKB was also more abundant in females, but fold differences between the two sexes were less pronounced. The dimorphic patterns/sex differences could be attributed mostly to the lack of estrogen negative feedback in aged women, as opposed to males in which testosterone negative feedback remains functional. However, we have to note that some sex differences may also reflect the organizational effects of a developmental sex steroid exposure. An important health consequence of the altered NKB signaling in postmenopausal women is the dysregulation of the heat dissipation center which seems to play a critical role in the pathogenesis of hot flushes [29]. In accordance with this concept, recent studies of mice have shown that the artificial activation of arcuate nucleus KP neurons evokes a heat-dissipation response which can be sensitized by ovariectomy [30]. Within this volume, Modi and Dhillo provide a review of the growing evidence supporting antagonism of the NKB receptor (NK3R) as a potential new treatment for menopausal hot flushes [31].

\section{Aging of KP Neurons in Males}

Our laboratory carried out a series of quantitative immunohistochemical experiments in an attempt to address the putative aging-related anatomical alterations of the $\mathrm{KP}$ and NKB systems in the human male [16]. The samples were arbitrarily subdivided into "young" ( $<50$ years) and "aged" ( $\geq 50$ years) groups. We assessed and compared between these two age groups the abundance of KP-IR and NKB-IR cell bodies, the size of NKB-IR perikarya, the regional density of KP-IR and NKB-IR fibers, the incidence of KP-IR and NKB-IR appositions onto GnRH-IR neurons, and the colocalization of KP and NKB in neuronal cell bodies and in afferents to GnRH-IR neurons. Overall, the abundance and labeling of NKB-IR neuronal elements exceeded those of the KP-IR structures. On the other hand, aging-related changes of the KP system were more pronounced than those of the NKB system. We identified robust aging-dependent enhancements in the regional densities of KP-IR perikarya and fibers and the incidence of contacts they established onto GnRH neurons (Fig. 2c). The abundance of NKB-IR perikarya and fibers and the number of inputs they provided for GnRH neurons also increased with age, albeit to low- er extents than did these parameters for KP. The regional densities of NKB-IR perikarya and fibers, and the incidence of afferent contacts they formed onto GnRH neurons, exceeded several times those of the KP-IR elements. In dual-immunofluorescence studies, the incidence of KP-IR NKB perikarya increased from $36 \%$ in young to $68 \%$ in aged men (Fig. 2a). Collectively, these immunohistochemical observations on human males suggest an aging-related robust enhancement in central KP signaling and moderate enhancement in central NKB signaling. Overall, these alterations may be compatible with a reduced negative sex steroid feedback to KP and NKB neurons. Middle aged/aged male subjects showed a moderate $22 \%$ age-dependent increase in the mean profile area of $\mathrm{NKB}$ neurons which was reminiscent of a previously reported mild (12\%) increase in the size of unidentified neurons in the INF of the aging men [32]. This phenomenon may be analogous to the much more robust hypertrophy of KP [4] and NKB [28] cells in postmenopausal women. As reviewed recently [33], serum testosterone and free testosterone levels decline with advancing age from the third decade onward with an average rate of 1 and $3 \%$, respectively, per year. Low levels of circulating sex steroids in middle aged/aged men may thus serve as the endocrine background for anatomical changes of $\mathrm{KP}$ and NKB neurons. It can be debated that the decreased levels of male sex hormones necessarily result from normal aging. Confounders include the increasing incidences of obesity and chronic health issues [33]. The most interesting aging-related changes in our studies were the increasing percentages of $\mathrm{KP}$-expressing $\mathrm{NKB}$ perikarya (Fig. 2a), NKB axons, and NKB inputs to GnRH neurons. The increased colocalization rates raise the intriguing possibility that a significant subset of NKB neurons only begins to cosynthesize $\mathrm{KP}$ as aging proceeds. This may be due to epigenetic derepression of the KISS1 gene in these cells.

\section{Recent Technical Advancement and Perspectives}

Recent technical advancements will allow us to ask previously unanswered questions about the hypothalamic neuronal network of human fertility and its changes during reproductive aging. These include:

\section{Generation of New Preprokisspeptin Antibodies for}

Immunohistochemical Experiments

$\mathrm{KP}$ antibodies used previously to study human KP neurons [5] were directed against the receptor ligands 
mouse KP-10 and human KP-54 [5]. The targeted sequences included the conserved C-terminal amidated RF or RY motif which is common to members of the RFamide peptide family, potentially causing erroneous antibody binding to cells like RF amide-related peptide neurons [34]. To eliminate this problem, new polyclonal antibodies have been designed and raised against different human preprokisspeptin (preproKP) peptide fragments in ways to exclude the C-terminal RF-amide motif of the receptor ligand KP-54 (aa 68-121 of NP_002247.3). This approach makes cross-reactions with unwanted members of the RF-amide peptide family very unlikely. Two products sold recently by Antibody Verify were generated in rabbits against aa 21-80 (AAS26420C) and aa 47106 (AAS27420C) of NP_002247.3. Results of dual-immunofluorescent experiments in our laboratory with the combined use of these and the sheep GQ2 reference KP54 antibodies [35] confirmed that the new products only recognize KP cells in immersion-fixed human hypothalamic tissues [36]. Recently, our laboratory has also designed an antigen in which an $\mathrm{N}$-terminal cysteine was added to a synthetic peptide corresponding to aa 70-93. The peptide was conjugated to keyhole limpet hemocyanin using the Sulfo-SMCC crosslinker and 5 mice were immunized intraperitoneally to generate antibodies in ascites fluid, as reported for other antigens [37]. Antibody production was carried out in accordance with the Council Directive of 24 November 1986 of the European Communities (86/609/EEC) and approved by the Animal Welfare Committee of the Institute of Experimental Medicine (No. PE/EA/1510-7/2018). One mouse provided excellent antibodies (BG\#01) which were collected by aspiring ascites fluid 8 days after booster injections. Positive control experiments used the triple-immunofluorescent labeling of hypothalamic sections from the INF of a postmenopausal woman (Fig. 3). Three different primary antibodies raised in different species (sheep, mouse, and rabbit, respectively) recognized essentially identical neurons and fibers. Triple-immunoreactivity of nearly all labeled structures indicates that preproKP antibodies will be applicable not only to label KP cell bodies but also to trace KP fiber projections. We occasionally observed single-labeling of a few scattered axons with the GQ2 antiserum against KP-54. This may reflect either the higher sensitivity or a negligible non-specific binding of this antiserum, although in vitro studies show virtually no cross-reactivity of this antiserum with several tested RFamide peptides [35]. These specificity control experiments were carried out with permission from the Regional and Institutional Committee of Science and Research
Ethics of Semmelweis University (SE-TUKEB 251/2016), in accordance with the Hungarian Law (1997 CLIV and 18/1998/XII.27. EÜM Decree/).

\section{Use of Perfusion-Fixed Human Brains to Analyze KP Neuron Synaptology}

In an attempt to study for the first time human KP neuron synaptology, recent studies from the Human Hypothalamus Research Unit of our laboratory (http://hhru. koki.hu/) used brain samples that were perfusion-fixed through the Willis circle 3-4 h post-mortem with a glutaraldehyde-containing fixative. The well-preserved ultrastructure of such samples allowed us to study the synaptic connectivity of human KP neurons with electron microscopy (Fig. 4a, b1, b2). IR axons formed axoaxonal contacts and established asymmetric axodendritic and axosomatic synapses with each other. KP terminals, many of which synapsed on dendritic spines, contained smallclear vesicles, in addition to dense-core granules. This finding, together with the asymmetric morphology of synapses, raised the possibility that the amino acid cotransmitter of KP neurons is glutamate. Indeed, high-frequency optogenetic stimulation of KNDy neurons in rodents evokes glutamatergic signaling onto rostral periventricular KP neurons [38], and KNDy neurons express vesicular glutamate transporter-2 (VGLUT2) mRNA [39] and immunoreactivity [40]. Moreover, VGLUT2 has also been detected in axon terminals of ovine KNDy neurons [41]. Although ultrastructural features of human KP terminals strongly indicate the use of glutamatergic cotransmission, we note that the direct demonstration of vesicular glutamate transporters in human KP terminals has not been successful in our recent dual-immunofluorescent experiments [12].

\section{Use of Diolistic Labeling with DiI to Study the KP \\ Dendritic Arbor and Spines}

A frequently encountered limitation of the immunohistochemical technique is the poor visualization of the distal dendrites and cell surface appendages. Accordingly, earlier immunohistochemical studies in our laboratory could only provide limited insight into the dendritic organization of the human KP system, leaving important fine structural details unexplored [5]. To overcome this limitation, in our recent study [12] we have random-labeled the KP cell membrane with a Helios Gene Gun using bullets loaded with tungsten beads to which the lipophilic dye, DiI was preabsorbed. Use of light tissue fixation and mild tissue permeabilization before the immunofluorescent detection of KP were important to 
achieve successful random-labeling of KP neurons in $100-\mu \mathrm{m}$-thick vibratome slices (Fig. 4c1-c3). The dendritic tree of KP neurons was found to branch sparsely. The mean length of non-truncated dendrites was $290 \mu \mathrm{m}$. The labeled axons emerged from the proximal dendrite or the cell body. The DiI labeling also visualized a large number of multiform spines on the KP somata and den- drites; these appendages remained entirely invisible using immunohistochemistry only. Postmortem labeling with DiI of KP neurons from different reproductive statuses is a promising approach for studying the aging-related morphological plasticity of the human KP system. In recent experiments on mice, KNDy neurons filled in vitro with biocytin exhibited an interesting steroid-dependent
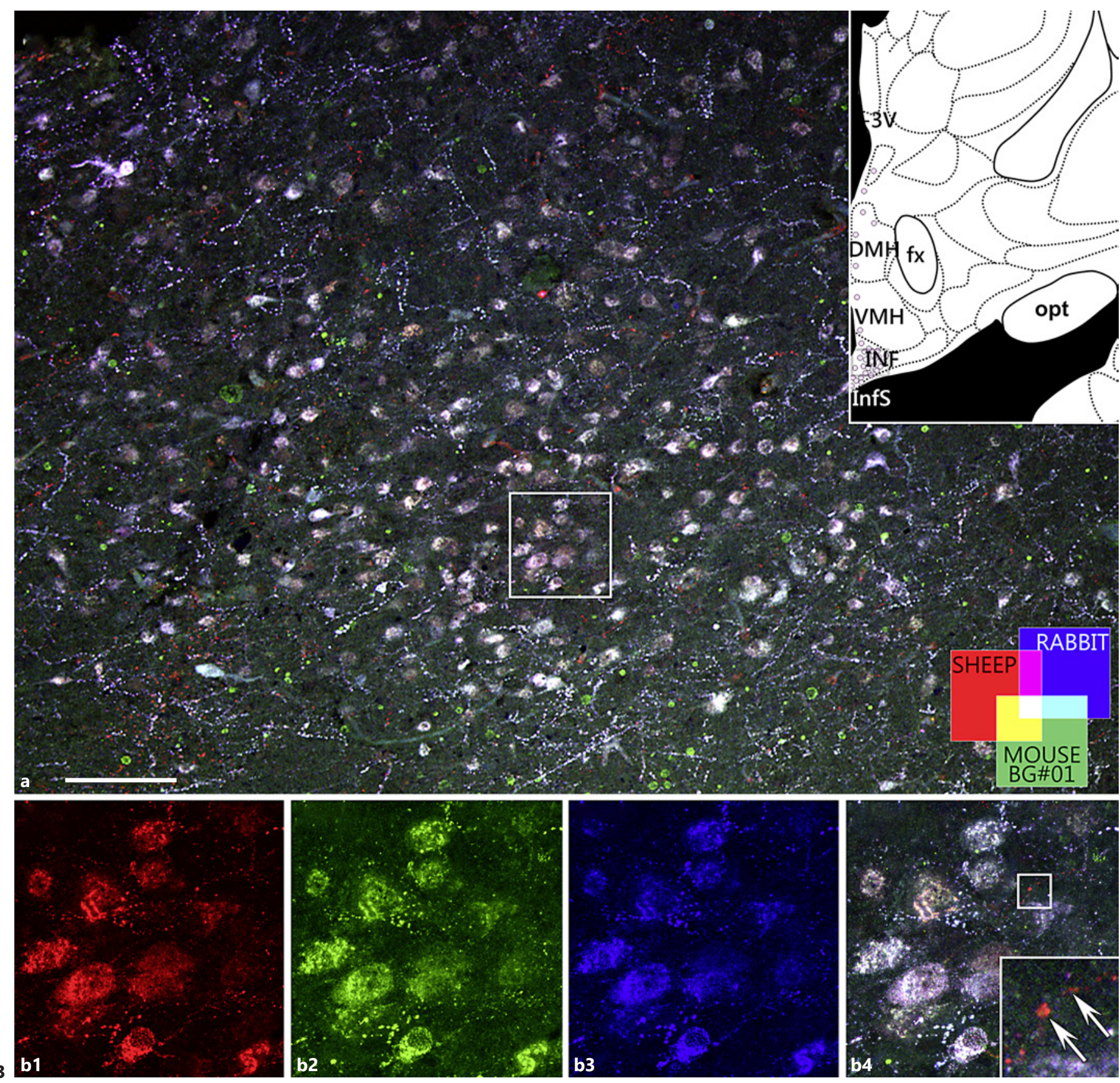

(For legend see next page.) 

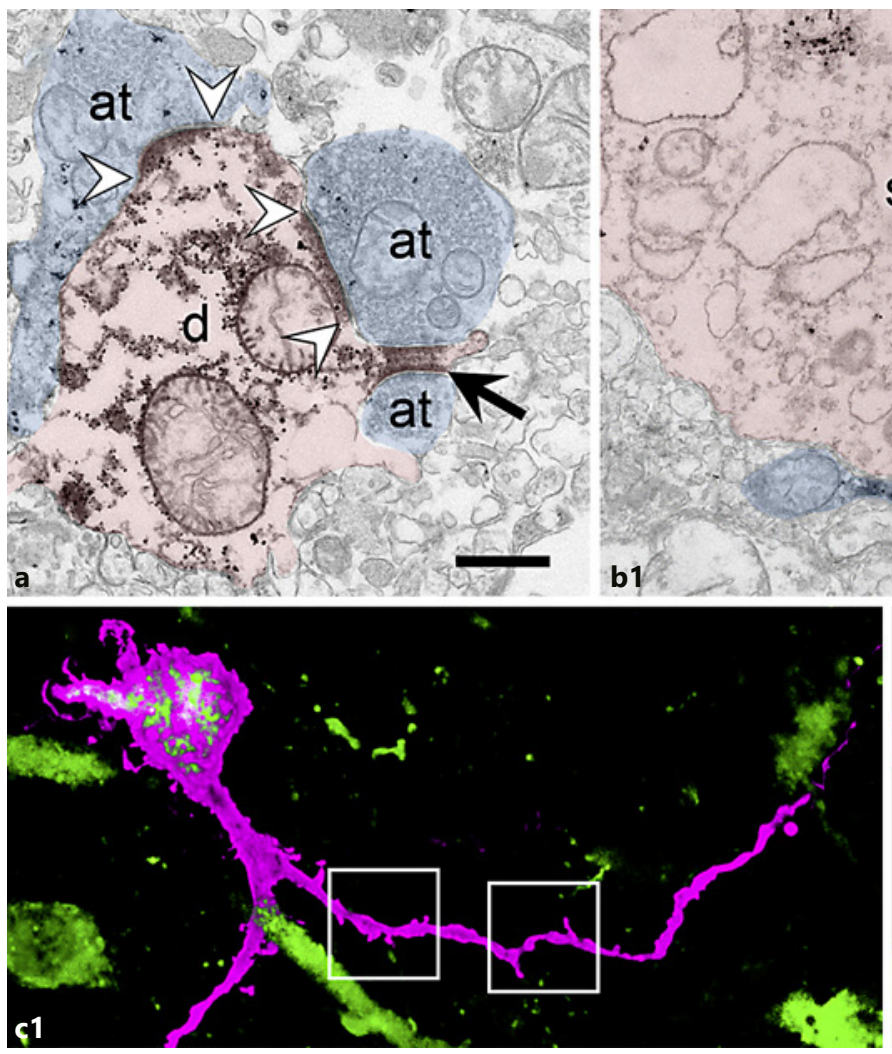

Fig. 4. Fine structure of human kisspeptin (KP) neurons studied using immunoelectron microscopy and random diolistic labeling with DiI. a, b1, b2 KP input to KP neurons has been studied with preembedding immunoelectron microscopy using perfusion-fixed brain samples from a 55-year-old male subject. KP-IR axon terminals (at; silver-gold intensified nickel-diaminobenzidine particles) form exclusively asymmetric synapses (arrowheads) on the dendrites ( $d$; a) and somata ( $s ; \mathbf{b 1}, \mathbf{b 2}$ ) of other KP neurons. The IR terminals contain both large dense-core ( $\varnothing$ 80-100 nm; white arrows in b2) and round small clear $(\varnothing 20-30$ $\mathrm{nm}$ ) vesicles, which, together with the asymmetric synaptic morphology, suggest the use of glutamatergic cotransmission. Black arrow in a points to a $\mathrm{KP} / \mathrm{KP}$ synaptic contact on a spine neck. c1-c3 Diolistic labeling of KP neurons with a Helios gene gun allows the visualization of the fine structure of the somatodendritic neuronal compartment. The KP-IR (green) neuron in c1 has been hit randomly by a tungsten bead preabsorbed with the lipophilic dye, DiI (magenta color). The uneven somatodendritic surfaces are caused by fungiform (c2) and filiform (c3) spines shown by arrowheads in high-power images which correspond to the framed areas in c1. Scale bars $=500 \mathrm{~nm}$ in $\mathbf{a}$ and $\mathbf{~ b 2}$, and $1 \mu \mathrm{m}$ in b1. Scale bar shown in $\mathbf{c} \mathbf{3}=20 \mu \mathrm{m}$ in $\mathbf{c} \mathbf{1}$ and $5 \mu \mathrm{m}$ in $\mathbf{c 2}$ and $\mathbf{c 3}$. Images were reproduced with permission from Takács et al. [12].
Fig. 3. Results of positive control experiments to confirm specificity of immunohistochemical labeling with newly available preprokisspeptin antibodies. a Low-power confocal image of a tripleimmunolabeled section from a postmenopausal woman illustrates that the distribution pattern of the KP signal is essentially identical using three primary antibodies from different host species. White color corresponds to triple-labeled neuronal elements in the merged red, green, and blue channels. b1-b4 High-power images of the framed region in a are shown in separate (b1-b3) and merged (b4) color channels. The reference KP-54 antiserum (GQ; b1) has been raised in sheep against aa 68-121 of NP_002247.3 [35]. Our polyclonal mouse KP antibodies (BG\#01) used in b2 have been generated in ascites fluid after immunizing a mouse intraperitoneally with an antigen comprising aa 70-93 of NP 002247.3. The commercially available rabbit antiserum used in $\mathbf{b} \overline{\mathbf{3}}$
(AAS26420C; Antibody Verify) has been directed against aa 21-80 of NP_002247.3. The secondary antibodies from Jackson ImmunoResearch Laboratories were conjugated to Cy3, FITC and Cy5, respectively, in b1-3. Note that the vast majority of cell bodies and processes are triple-labeled, although very few fibers occasionally exhibit KP-54 immunoreactivity only. This extra labeling may reflect either the higher sensitivity or a negligible non-specific binding of this antiserum. The two preprokisspeptin antibodies provide excellent options to label KP neurons as well as fibers in future immunohistochemical studies. $\mathrm{DMH}$, dorsomedial nucleus of the hypothalamus; fx, fornix; INF, infundibular nucleus; InfS, infundibular stalk; opt, optic tract; VMH, ventromedial nucleus of the hypothalamus; $3 \mathrm{~V}$, third ventricle. Scale bar shown in $\mathbf{a}=140 \mu \mathrm{m}$ in a, $50 \mu \mathrm{m}$ in b1-b4, and $15 \mu \mathrm{m}$ in b4 inset. 
structural plasticity in that they responded to estradiol treatment with reduced cell size and dendritic spine density [13]. Assuming a similar regulation in the human, we predict higher spine densities on KP neurons of postmenopausal versus premenopausal women. DiI labeling will also offer an excellent approach to study pubertal changes of the dendritic tree via the comparison of prepubertal to adult samples.

\section{Use of Short Postmortem Time Tissues for in situ Hybridization Experiments}

Several laboratories including our own (http://hhru. koki.hu/) have access to human tissues in which appropriate RNA preservation allows in situ hybridization experiments. Important early publications with a focus on estrogen-responsive neurons of the INF used isotopically labeled oligoDNA probes on postmortem tissues which provided sufficient sensitivity to detect the mRNAs encoding estrogen receptor- $\alpha$ [27], substance P [28], NKB [28], KP [4], and prodynorphin [20]. A recent technical advancement was the development of the revolutionary RNAScope in situ hybridization technology. This technique may provide extremely high specificity and sensitivity for future multiple-labeling in situ hybridization experiments. It is worth to note that the use of fluorescent signal detection to study human KP cells may be challenging due to the high tissue autofluorescence caused by spotty lipofuscin deposits especially in samples from aged subjects. Prior to immunofluorescent experiments, we routinely quench this autofluorescence using tissue delipidation with acetone, followed by a $0.3 \%$ Sudan black treatment of the sections in $70 \%$ ethanol for $30 \mathrm{~min}$. For detailed protocol, see [42]. In in situ hybridization experiments, quenching of lipofuscin autofluorescence with Sudan Black is better placed after the fluorescent signal detection steps, keeping also in mind that fluorochromes have to be chosen to withstand use of the above organics. In recent years, several alternatives to Sudan Black became available commercially, including TrueBlack from Biotium.

\section{Newly Available Techniques for Single-Cell}

Transcriptomics

Modern single-cell microarray and RNA-sequencing techniques [43] with high-throughput approaches enable the interrogation of RNA sequences on a large scale. The majority of single-cell techniques like Drop-seq [44] start with living tissues and cells with well-preserved RNA which could not be accessed easily from the human hypothalamus. Second, using dissection material, postmor- tem delay before optimal tissue processing may already compromise cellular RNA integrity, and freshly dissected surgical samples are not readily available from this deep brain site. In mice, transgenic expression of cell type-specific fluorescent markers can be achieved and used to collect cell type-specific RNA following the isolation of the labeled cell population with FACS, laser capture microdissection (LCM), or a patch pipette. An additional technical challenge in human tissues will be to preserve RNA integrity while introducing cell type-specific labels to KP neurons. Because of these technical difficulties, RNA-seq methods could not so far be carried out on human KP neurons. Laboratories are currently working on the development of pulse-immunolabeling approaches which can preserve RNA integrity while visualizing individual neurons in unfixed or only lightly fixed postmortem brains. Once this task is achieved, LCM can be used to dissect and pool individual KP-IR neurons for subsequent analysis on the Illumina platform. Promising alternative approaches compatible with the use of frozen postmortem brain tissues include the recently developed DroNc-seq technology, a high-throughput single nucleus RNA-seq method [45].

\section{Unresolved Tasks}

\section{Single-Cell Transcriptomics of KP Cells}

As mentioned above, multiple technical requirements will need to be met to study the transcriptome profile of human KP cells. The immunohistochemical identification of KP neurons appears to require at least a short fixation with formalin. In itself, this fixation step can already somewhat compromise RNA integrity and quality. Then, the technical parameters of immunohistochemical pulselabeling have to be optimized. Brief use of RNase-free antibody and buffer solutions containing RNase inhibitors will be key to maintain RNA integrity during the immunohistochemical visualization of KP cells. LCM can be used subsequently to collect RNA from the immunolabeled cells, followed by RNA-Seq. The identification of steroid and neuropeptide receptors in these neurons and aging-related changes in the transcriptome profile of the KP cell will be particularly interesting.

\section{Identification of New Hypothalamic and \\ Extrahypothalamic Target Cells to KP Neurons}

From the putative target cells of human KP projections, only GnRH [5] and KP [12] neurons have been studied and identified so far. As KP fibers are quite widespread espe- 
cially in the medial hypothalamus [5], many additional target neurons are likely to exist. Several KP target neurons have already been identified in rodents. These include POMC [46], AgRP [46] and oxytocin cells [47]. The issue of whether or not these cells are also innervated by KP fibers in the human, as well as the location and neurochemistry of additional KP target neurons, will require clarification. It will also remain an interesting challenge to visualize the thermoregulatory pathway proposed to account for hot flushes in postmenopausal women [29].

\section{Characterization of the Afferent Connectivity of KP Neurons}

In a recent study, we demonstrated glutamatergic and GABAergic inputs to human KP neurons [12]. The phenotypes and sources of other specific inputs require immunohistochemical clarification. A particularly interesting task will be to identify the putative pathways that mediate metabolic effects to the reproductive axis.

\section{Characterization of the Sexually Dimorphic KP Cell \\ Population in the Rostral Periventricular Area}

We now possess multiple optional preproKP antibodies including our own (Fig. 3), to study the neurochemical characteristics, projections, target cells and the age- and hormone-dependent plasticity of the sexually dimorphic KP cell population observed originally in the rostral periventricular area of young human females [5]. Sexual dimorphism of the equivalent rodent cell group develops in response to the perinatal sex steroid exposure of males [48]. This makes it very likely that early life organizational events contribute similarly to the reported sex differences of this cell group [5] in humans.
Determining the Sex Steroid-, Puberty-, and Age-Dependent Anatomical and Molecular Plasticity of KP Neurons

Quantitation of immunohistochemical labeling patterns $[15,16]$ and currently unavailable routine approaches of single-cell transcriptomics will need to determine how sex steroids, puberty, and age influence the transcriptome and proteome profiles of human KP neurons.

\section{Conclusion}

Although critical information has accumulated in recent years from animal experiments, laboratory rodents sometimes have limited translational value as models for the hypothalamic regulation of the human reproductive cycle and fertility. Therefore, studies of the postmortem human hypothalamus will remain indispensable in the future. Development and use of high-resolution and high-throughput molecular and anatomical techniques on human tissues will be critically important to clarify the basic mechanisms of GnRH/LH pulsatility, sex steroid feedback, puberty, and reproductive aging.

\section{Disclosure Statement}

The authors have nothing to disclose.

\section{Funding Sources}

The research leading to these results has received funding from the National Science Foundation of Hungary (K112669 and K128317 to E.H. and PD125393 to K.S.) and the Hungarian Brain Research Program (2017-1.2.1-NKP-2017-00002 to E.H.).

\section{References}

1 de Roux N, Genin E, Carel JC, Matsuda F, Chaussain JL, Milgrom E. Hypogonadotropic hypogonadism due to loss of function of the KiSS1-derived peptide receptor GPR54. Proc Natl Acad Sci USA. 2003 Sep;100(19):109726.

2 Seminara SB, Messager S, Chatzidaki EE, Thresher RR, Acierno JS Jr, Shagoury JK, et al. The GPR54 gene as a regulator of puberty. N Engl J Med. 2003 Oct;349(17):1614-27.

3 Hrabovszky E. Neuroanatomy of the human hypothalamic kisspeptin system. Neuroendocrinology. 2014;99(1):33-48.
4 Rometo AM, Krajewski SJ, Voytko ML, Rance NE. Hypertrophy and increased kisspeptin gene expression in the hypothalamic infundibular nucleus of postmenopausal women and ovariectomized monkeys. J Clin Endocrinol Metab. 2007 Jul;92(7):2744-50.

5 Hrabovszky E, Ciofi P, Vida B, Horvath MC, Keller E, Caraty A, et al. The kisspeptin system of the human hypothalamus: sexual dimorphism and relationship with gonadotropinreleasing hormone and neurokinin $\mathrm{B}$ neurons. Eur J Neurosci. 2010 Jun;31(11):198498.
6 Herbison AE. Estrogen positive feedback to gonadotropin-releasing hormone $(\mathrm{GnRH})$ neurons in the rodent: the case for the rostral periventricular area of the third ventricle (RP3V). Brain Res Brain Res Rev. 2008 Mar; 57(2):277-87.

7 Hess DL, Wilkins RH, Moossy J, Chang JL, Plant TM, McCormack JT, et al. Estrogen-induced gonadotropin surges in decerebrated female rhesus monkeys with medial basal hypothalamic peninsulae. Endocrinology. 1977 Oct;101(4):1264-71. 
8 Knobil E. The neuroendocrine control of the menstrual cycle. Recent Prog Horm Res. 1980;36:53-88.

9 Hall JE, Taylor AE, Martin KA, Rivier J, Schoenfeld DA, Crowley WF Jr. Decreased release of gonadotropin-releasing hormone during the preovulatory midcycle luteinizing hormone surge in normal women. Proc Natl Acad Sci USA. 1994 Jul;91(15):6894-8.

10 Ottowitz WE, Dougherty DD, Fischman AJ, Hall JE. [18F]2-fluoro-2-deoxy-D-glucose positron emission tomography demonstration of estrogen negative and positive feedback on luteinizing hormone secretion in women. J Clin Endocrinol Metab. 2008 Aug; 93(8):3208-14.

11 Di Giorgio NP, Semaan SJ, Kim J, López PV, Bettler B, Libertun C, et al. Impaired GABAB receptor signaling dramatically up-regulates Kiss1 expression selectively in nonhypothalamic brain regions of adult but not prepubertal mice. Endocrinology. 2014 Mar;155(3): 1033-44.

12 Takács S, Bardóczi Z, Skrapits K, Göcz B, Váczi V, Maglóczky Z, et al. Post mortem singlecell labeling with DiI and immunoelectron microscopy unveil the fine structure of kisspeptin neurons in humans. Brain Struct Funct. 2018 Jun;223(5):2143-56.

13 Cholanian M, Krajewski-Hall SJ, McMullen NT, Rance NE. Chronic oestradiol reduces the dendritic spine density of KNDy (kisspeptin/ neurokinin B/dynorphin) neurones in the arcuate nucleus of ovariectomised Tac2-enhanced green fluorescent protein transgenic mice. J Neuroendocrinol. 2015 Apr;27(4):253-63.

14 Skrapits K, Borsay BA, Herczeg L, Ciofi P, Liposits Z, Hrabovszky E. Neuropeptide co-expression in hypothalamic kisspeptin neurons of laboratory animals and the human. Front Neurosci. 2015 Feb;9:29.

15 Hrabovszky E, Molnár CS, Sipos MT, Vida B, Ciofi P, Borsay BA, et al. Sexual dimorphism of kisspeptin and neurokinin B immunoreactive neurons in the infundibular nucleus of aged men and women. Front Endocrinol (Lausanne). 2011 Dec;2:80.

16 Molnár CS, Vida B, Sipos MT, Ciofi P, Borsay BA, Rácz K, et al. Morphological evidence for enhanced kisspeptin and neurokinin B signaling in the infundibular nucleus of the aging man. Endocrinology. 2012 Nov; 153(11): 5428-39.

17 Hrabovszky E, Sipos MT, Molnár CS, Ciofi P, Borsay BA, Gergely P, et al. Low degree of overlap between kisspeptin, neurokinin B, and dynorphin immunoreactivities in the infundibular nucleus of young male human subjects challenges the KNDy neuron concept. Endocrinology. 2012 Oct;153(10):497889.

18 Goodman RL, Lehman MN, Smith JT, Coolen LM, de Oliveira CV, Jafarzadehshirazi MR, et al. Kisspeptin neurons in the arcuate nucleus of the ewe express both dynorphin A and neurokinin B. Endocrinology. 2007 Dec;148(12): 5752-60.
19 Navarro VM, Gottsch ML, Chavkin C, Okamura H, Clifton DK, Steiner RA. Regulation of gonadotropin-releasing hormone secretion by kisspeptin/dynorphin/neurokinin B neurons in the arcuate nucleus of the mouse. J Neurosci. 2009 Sep;29(38):1185966.

20 Rometo AM, Rance NE. Changes in prodynorphin gene expression and neuronal morphology in the hypothalamus of postmenopausal women. J Neuroendocrinol. 2008 Dec; 20(12):1376-81.

21 Nikoshkov A, Hurd YL, Yakovleva T, Bazov I, Marinova Z, Cebers G, et al. Prodynorphin transcripts and proteins differentially expressed and regulated in the adult human brain. FASEB J. 2005 Sep;19(11):1543-5.

22 Porteous R, Petersen SL, Yeo SH, Bhattarai JP, Ciofi P, de Tassigny XD, et al. Kisspeptin neurons co-express met-enkephalin and galanin in the rostral periventricular region of the female mouse hypothalamus. J Comp Neurol. 2011 Dec;519(17):3456-69.

23 Kalló I, Vida B, Deli L, Molnár CS, Hrabovszky E, Caraty A, et al. Co-localisation of kisspeptin with galanin or neurokinin B in afferents to mouse GnRH neurones. J Neuroendocrinol. 2012 Mar;24(3):464-76.

24 Hrabovszky E, Borsay BA, Rácz K, Herczeg L, Ciofi P, Bloom SR, et al. Substance P immunoreactivity exhibits frequent colocalization with kisspeptin and neurokinin $\mathrm{B}$ in the human infundibular region. PLoS One. 2013 Aug;8(8):e72369.

25 Skrapits K, Borsay BA, Herczeg L, Ciofi P, Bloom SR, Ghatei MA, et al. Colocalization of cocaine- and amphetamine-regulated transcript with kisspeptin and neurokinin B in the human infundibular region. PLoS One. 2014 Aug;9(8):e103977.

26 Sheehan HL, Kovács K. The subventricular nucleus of the human hypothalamus. Brain. 1966 Sep;89(3):589-614.

27 Rance NE, McMullen NT, Smialek JE, Price DL, Young WS 3rd. Postmenopausal hypertrophy of neurons expressing the estrogen receptor gene in the human hypothalamus. J Clin Endocrinol Metab. 1990 Jul;71(1):7985.

28 Rance NE, Young WS 3rd. Hypertrophy and increased gene expression of neurons containing neurokinin- $\mathrm{B}$ and substance- $\mathrm{P}$ messenger ribonucleic acids in the hypothalami of postmenopausal women. Endocrinology. 1991 May;128(5):2239-47.

29 Rance NE, Dacks PA, Mittelman-Smith MA, Romanovsky AA, Krajewski-Hall SJ. Modulation of body temperature and $\mathrm{LH}$ secretion by hypothalamic KNDy (kisspeptin, neurokinin $B$ and dynorphin) neurons: a novel hypothesis on the mechanism of hot flushes. Front Neuroendocrinol. 2013 Aug;34(3): 211-27.

30 Padilla SL, Johnson CW, Barker FD, Patterson MA, Palmiter RD. A neural circuit underlying the generation of hot flushes. Cell Reports. $2018 \mathrm{Jul} ; 24(2): 271-7$.
31 Modi M, Dhillo WS: Neurokinin 3 receptor antagonism - a novel treatment for menopausal hot flushes. Neuroendocrinology. 2018, DOI 10.1159/000495889.

32 Rance NE, Uswandi SV, McMullen NT. Neuronal hypertrophy in the hypothalamus of older men. Neurobiol Aging. 1993 Jul-Aug; 14(4):337-42.

33 Decaroli MC, Rochira V. Aging and sex hormones in males. Virulence. 2017 Jul;8(5): 545-70.

34 Franceschini I, Yeo SH, Beltramo M, Desroziers $\mathrm{E}$, Okamura $\mathrm{H}$, Herbison $\mathrm{AE}$, et al. Immunohistochemical evidence for the presence of various kisspeptin isoforms in the mammalian brain. J Neuroendocrinol. 2013 Sep; 25(9):839-51.

35 Dhillo WS, Chaudhri OB, Patterson M, Thompson EL, Murphy KG, Badman MK, et al. Kisspeptin-54 stimulates the hypothalamic-pituitary gonadal axis in human males. Clin Endocrinol Metab. 2005 Dec;90(12): 6609-15.

36 Borsay BA, Skrapits K, Herczeg L, Ciofi P, Bloom SR, Ghatei MA, et al. Hypophysiotropic gonadotropin-releasing hormone projections are exposed to dense plexuses of kisspeptin, neurokinin $B$ and substance $p$ immunoreactive fibers in the human: a study on tissues from postmenopausal women. Neuroendocrinology. 2014;100(23): $141-52$

37 Skrapits K, Kanti V, Savanyú Z, Maurnyi C, Szenci O, Horváth A, et al. Lateral hypothalamic orexin and melanin-concentrating hormone neurons provide direct input to gonadotropin-releasing hormone neurons in the human. Front Cell Neurosci. 2015 Sep; 9:348

38 Qiu J, Nestor CC, Zhang C, Padilla SL, Palmiter RD, Kelly MJ, et al. High-frequency stimulation-induced peptide release synchronizes arcuate kisspeptin neurons and excites GnRH neurons. eLife. 2016 Aug;5:5.

39 Cravo RM, Margatho LO, Osborne-Lawrence S, Donato J Jr, Atkin S, Bookout AL, et al. Characterization of Kiss1 neurons using transgenic mouse models. Neuroscience. 2011 Jan;173:37-56.

40 Ciofi P, Leroy D, Tramu G. Sexual dimorphism in the organization of the rat hypothalamic infundibular area. Neuroscience. 2006 Sep;141(4):1731-45.

41 Merkley CM, Coolen LM, Goodman RL, Lehman MN. Evidence for changes in numbers of synaptic inputs onto kndy and gnrh neurones during the preovulatory lh surge in the ewe. J Neuroendocrinol. 2015 Jul;27(7): 624-35.

42 Mihály E, Fekete C, Tatro JB, Liposits Z, Stopa EG, Lechan RM. Hypophysiotropic thyrotropin-releasing hormone-synthesizing neurons in the human hypothalamus are innervated by neuropeptide $\mathrm{Y}$, agouti-related protein, and alpha-melanocyte-stimulating hormone. J Clin Endocrinol Metab. 2000 Jul;85(7):2596-603. 
43 Hrdlickova R, Toloue M, Tian B. RNA-Seq methods for transcriptome analysis. Wiley Interdiscip Rev RNA. 2017 Jan;8(1):8.

44 Macosko EZ, Basu A, Satija R, Nemesh J, Shekhar K, Goldman M, et al. Highly parallel genome-wide expression profiling of individual cells using nanoliter droplets. Cell. 2015 May;161(5):1202-14.
45 Habib N, Avraham-Davidi I, Basu A, Burks T, Shekhar K, Hofree M, et al. Massively parallel single-nucleus RNA-seq with DroNc-seq. Nat Methods. 2017 Oct;14(10):955-8.

46 Nestor CC, Qiu J, Padilla SL, Zhang C, Bosch MA, Fan W, et al. Optogenetic stimulation of arcuate nucleus kiss1 neurons reveals a steroid-dependent glutamatergic input to pomc and agrp neurons in male mice. Mol Endocrinol. 2016 Jun;30(6):630-44.
47 Seymour AJ, Scott V, Augustine RA, Bouwer GT, Campbell RE, Brown CH. Development of an excitatory kisspeptin projection to the oxytocin system in late pregnancy. J Physiol. 2017 Feb;595(3):825-38.

48 Clarkson J, Herbison AE. Postnatal development of kisspeptin neurons in mouse hypothalamus; sexual dimorphism and projections to gonadotropin-releasing hormone neurons. Endocrinology. 2006 Dec;147(12):5817-25. 